
$\$$ Research Square
Preprints are preliminary reports that have not undergone peer review.
They should not be considered conclusive, used to inform clinical practice, or referenced by the media as validated information.

\title{
"Knowledge, Attitudes and Practices of Health Legislation and Regulations by Dentists and Stomatologists in the Valencian Community: A KAP Analysis".
}

Martina Sánchez Gisbert ( $\square$ martina.sanchez@uchceu.es )

Universidad Cardenal Herrera, CEU Universities.

Marina Gisbert Grifo

University of Valencia

Chirag C. Sheth

Universidad Cardenal Herrera, CEU Universities.

\section{Research Article}

Keywords: Legislation, health regulations, expertise, dental law, dentistry

Posted Date: February 18th, 2021

DOI: https://doi.org/10.21203/rs.3.rs-208727/v1

License: (1) This work is licensed under a Creative Commons Attribution 4.0 International License. Read Full License 


\section{Abstract}

Background: The main objective of this study is to analyse the background and knowledge, attitudes and practices of Spanish dentists and stomatologists registered in Alicante, Castellón and Valencia, the three provinces that make up the Valencian Community, with regard to current Spanish health legislation and regulations, and to try to quantify the relationship between level of training, specialisation, work experience, position and workplace, and degree of knowledge.

Methods: An anonymous survey was designed, consisting of thirty-three multiple-choice questions, checked beforehand by a statistician and validated by nine dentists and stomatologists from different specialisations, via an online platform called SurveyMonkey ${ }^{\circledR}$. The validated survey included questions regarding their professional background and key questions regarding current dental law and expertise. The link and QR code (Quick Response) for taking the survey was sent via the official email address of each province's College of Dentists and Stomatologists, so that members could take the survey online for a limited period of time.

Results: Members' level of knowledge of health legislation and regulations in the Valencian Community is moderate, with only $63 \%$ of the questions answered correctly. Neither their level of education nor work experience correlates significantly with their degree of knowledge. Dentists specialising in General and Aesthetics Dentistry were found to be more knowledgeable about ethical issues. Regarding the workplace, those working as university teachers tended to stand out from the other professionals in terms of legal and ethical knowledge whilst self-employed and employee dentists show a lower level of knowledge than the rest of the sample.

Conclusions: The conclusions obtained from this study highlight the need for dentists to complete and update their knowledge of current health legislation, as having proper knowledge is a means of avoiding possible legal problems, which not only means better legal protection for the dentist but is also a means of guaranteeing adequate patient care.

\section{Background}

Dentistry as a profession has gained importance over time due to the increase in demand for dental services, resulting not only from the appearance of caries, but also due to the increase in demand for aesthetic treatments such as veneers or whitening from the patient themselves, in addition to its technical development and consolidation as a specialisation, with its own specific scientific field of knowledge and practice (1).

The dental profession has undergone a major, fast-paced revolution in recent years. In 2009, at the request of the Official College of Dentists and Stomatologists of Valencia, a report regarding the demographics of the Dental Profession in the Province of Valencia was published, showing that the number of dentists in Valencia had quadrupled in the 20 years since the mid-1980s, rising from almost 6,000 inhabitants per dentist to less than 2,000 (2). These figures have continued to rise steadily, largely owing to the existence of many private universities in the province of Valencia itself. The College of Dentists and Stomatologists report 2,664 members in the province of Valencia, 337 in the province of Castellón and 1,185 in the province of Alicante, these being the three provinces that make up the Valencian Community. This brings the total number of members to 4,186 in the Valencian Community alone, a community with a total population of 5057353 inhabitants in the year 2020. 
The World Dental Federation recognises that dentistry is evolving and becoming more complex for a number of reasons, one of which is that patients have greater access to information and there is a growing interest in aesthetics and this development is creating new ethical challenges. Hence, there is a need for ethical awareness, reflection and guidance, as well as the need to maintain a dynamic and understandable code of ethics in the practice of dentistry (3).

Law and ethics are an integral part of medical and dental professional practice. The subject of Legal and Forensic Dentistry forms an integral part of practitioner training and encompasses an understanding of the broader issues of dental practice, including ethics, medical-legal considerations and the management and maintenance of a safe working environment (4). In an article by Garbin et al., it is noted that dentists were negligent of legal and ethical dental issues, and further research should be carried out to either confirm or address this fact (5). This, coupled with the findings of the article by Dhanappa et al., allows me to state that there is a need for proper education of graduates to raise their awareness of the aspects of legal education and maintenance of professional ethical conduct in health care (6). And as Avon SL and Ryan F.S. conclude, each practitioner has a responsibility to understand the forensic implications associated with the practice of their profession and must be aware of their responsibility $(7,8)$.

Patients today are more aware of their right to compensation and consequently dentists should be aware of the laws that govern them (9). Until just a few years ago, the prospect of being involved in legal proceedings was a concern for a large part of the population, who tried to avoid it as much as possible. Today, this mentality is changing. Society as a whole is more familiar, via the media, with other judicial processes and has fewer qualms about becoming involved in them (10).

Both patient safety and professional liability are major concerns throughout the world. The increasing risk of malpractice litigation and medical liability insurance premiums have caused widespread concern regarding their effects on medical care. The high risk of litigation changes the practice of the specialist and is one of the most frequently cited factors influencing their decision on whether to provide dental care or not. The increasing trend of claims for malpractice for adverse events has also been described and Oral and Maxillofacial Surgery professionals are acutely aware of the current problem (11). Dental care providers are obligated to deal with legal issues. It is therefore essential that physicians and dentists recognise the basic legal concepts of medical malpractice (12).

This is compounded by the fact that the ethical standards of the dental profession are in steady decline due to the market-driven system. An understanding of the legal aspects provides protection against litigation. It provides a practical implication for understanding the significance of dental history, radiographs, photos and models, because legally, the dentist's written records carry more weight than the patient's own recollections (13).

Finally, the most important reason is that Legal Dentistry will provide us with the knowledge to defend the rights of citizens, when the dentist, in the exercise of their professional duties, is placed in the position of guarantor of the rights of patients (14).

Thus, for all the reasons given above, we designed this study to ascertain the level of knowledge of current health legislation and regulations amongst dentists in the Valencian Community. We believe that the ignorance of the law does not excuse non-compliance with it. 


\section{Methods}

The main aim of this analytical and descriptive study was to objectively determine the level of knowledge of dentists and stomatologists in the three provinces of the Valencian Community regarding current health legislation and regulations. Specifically, the purpose was to quantify the dentists' degree of knowledge in relation to five variables: the dentists' level of training, specialisation, work experience, place and position at work related to their degree of knowledge.

For this purpose, a KAP survey (knowledge, attitudes and practices) regarding current health legislation was designed for dentists and stomatologists in the Valencian Community (Additional file 1). The survey design was statistician-supported and validated by nine dentists from different specialisations, to verify that it was comprehensible, pleasant and specific to the subject it was intended to evaluate. The respondents' identity was kept confidential, as they were initially assigned an IP (Internet Protocol) code or address, which is a numerical representation that uniquely identifies a particular interface on the network.

After answering ten initial questions on various issues of their professional background, they went on to assess their specific knowledge with twenty-three questions addressing the most important issues in current dental law and expertise, divided into three main sections. The first, on ethical knowledge, comprised questions on ethics, deontology and collegial organisation. The second, on knowledge of the law, covered issues such as requirements for the legal practice of dentistry, the rights and obligations of dentists and patients, the professional responsibility of the dentist, dental confidentiality and privacy. The third and last section dealt with dental-legal documentation, containing questions about informed consent, medical records and dental-legal, public and private expertise.

These twenty-three questions were multiple-choice questions, with four options, only one of which was correct, and wrong answers were did not cancel out correct responses. This survey was conducted on a commercial platform called SurveyMonkey ${ }^{\circledR}$, a useful tool that allows the surveys and their QR code to be sent via the professional association's official email address, thus enabling participants to complete the survey anonymously and online.

The study received the approval of the Ethics Committee for Biomedical Research (Additional file 2) of the International Doctoral Programme CEINDO at the CEU Cardenal Herrera University of Valencia. Following this, the lead investigator contacted the three Official Colleges of Dentists and Stomatologists of the Valencian Community, who approved the project via their scientific committees, and agreed to distribute the study.

The study population was all registered dentists in the Valencian Community, comprising 1185 dentists and stomatologists registered with the Official College of Dentists and Stomatologists of Alicante, the 337 dentists registered with the Official College of Dentists of Castellón and the 2664 dentists and stomatologists registered with the Official College of Dentists and Stomatologists of Valencia. College registered dentists received the survey via email, and were allowed to complete it between 16 January 2020 and 9 March 2020. Following the survey activity deadline, data were collected from the platform and statistical analysis was carried out.

Data analysis was carried out in two broad categories: a descriptive section and a bivariate inferential section. The descriptive analysis of the survey responses was in the form of tables containing the most relevant statistical data: absolute and relative frequencies for categorical variables and mean, standard deviation, 
minimum, maximum and median for continuous variables. For the inferential analysis, a series of bivariate statistical methods were used to address the stated objectives, Chi-squared tests of association were used to assess the relationship between the adequacy of the responses and the personal and professional background of the participant. If the dispersion of the contingency tables was excessive, non-parametric Mann-Whitney and Kruskal-Wallis tests were used to assess the homogeneity of the distributions in 2 or more independent groups. The influence of participant background on this new score was assessed using t-student tests and variance analysis. The significance level used in the analyses was $5 \%(a=0.05)$.

\section{Results}

\section{Sociodemographic results}

The final research sample consisted of 204 responding professionals registered in the three Official Colleges of Dentists and Stomatologists of the Valencian Community who answered the survey. Regarding the background of the respondents, $57.3 \%$ were registered in Valencia, $31.4 \%$ in Alicante and $11.3 \%$ in Castellón.

Of these, 64 were male $(32.7 \%)$ and 132 were female $(67.3 \%)$. The mean age ( \pm standard deviation) was $39.8 \pm$ 11.1 years, with a range between 23 and 67 years. The most common level of qualification was "licensed dentist" ("LD"; pre-1999 [Bologna declaration qualification]; 71.1\%), but there were also "dental graduates" ("DG"; post-1999 [Bologna declaration qualification]; 18.6\%) and those graduates in medicine with specialization in Dentistry ("GM"; $10.3 \%$ ). 89.2\% received this training entirely in Spain or shared with another country, as in the case of $4.2 \%$ of the respondents. $85.3 \%$ of the sample had acquired additional academic training, usually a Master's degree.

\section{Analysis by college (geographical)}

Analysing the results obtained from the survey in the three colleges of the Valencian Community, based on the percentage of correct questions by college, it was found that dentists or stomatologists who took the survey, correctly scored an average of $61.9 \%$ of the questions in the first section on ethical knowledge, $65.3 \%$ of the questions in the second section on legislative knowledge and $62.2 \%$ of the questions in the third section on dental-legal documentation, which meant that $63.4 \%$ of all the questions in the questionnaire were answered correctly, as can be seen in Fig. 1, overall percentage of questions answered correctly, the mean and standard deviation for the Valencian Community.

Figure 1: Overall percentage of questions answered correctly, the mean and standard deviation for the Valencian Community.

The overall score was 6.34 out of 10. Therefore, it can be concluded that dentists' and stomatologists' general level of knowledge of current health legislation and regulations was average in the Valencian Community and similar for each of the three sections considered.

Question 17 about the offences for which the dentist may be criminally liable and question 25 about fundamental rights related to consent were the most successfully answered questions, both with $93.1 \%$ correct answers. However, question 31, on expert examinations, was the question with the highest percentage of unfamiliarity of the whole test, with $7.4 \%$ not knowing or not answering. And question 20 , which dealt with the 
question of what to do if a patient refuses to pay the dentist's fee, was the one where the respondents failed the most, with the highest percentage of incorrect answers of the whole test, $90.2 \%$, as it can be seen in Fig. 2 , questions with greatest number of correct, incorrect and DKN/NA responses across all respondents. Q17 and Q25 were most answered correctly. Q20 had the greatest proportion of incorrect answers whilst Q31 had the greatest proportion of DNK/NA answers. DNK/NA: Doesn't know/ no answer.

In order to measure the relationship between level of education, specialisation, work experience, place and status at work and degree of knowledge, the level of knowledge was analysed according to the result of the Chi-squared test of independence and the F-test of the 1-way ANOVA model and/or the t-test for independent samples, depending on each variable.

\section{Analysis by level of training/education}

With regard to the specialisation of the professionals, as can be seen in Fig. 3, distribution of the sample by specialisation, $60.3 \%$ practised General Dentistry and to a lesser extent other specialisations (as this was a question where the professional could tick several options, the sum of the percentages exceeds $100 \%$ ), followed by other specialisations. In second place, Endodontics was selected by $36.8 \%$ of the respondents and in third place, Prosthodontics, with $30.4 \%$.

$59.8 \%$ of the respondents had more than 10 years of work experience and $85.3 \%$ of them worked in urban areas. With regard to where they practised their professional activity, the majority, $52.2 \%$, did so in their own private dental clinic and $51.7 \%$ in another private dental clinic, and with regard to the professional category that defined the interviewee, the majority, 52.9\%, were self-employed.

Thus, with regard to the level of education, only the results of two questions were statistically significant: question 16, where, when faced with evidence of unqualified practice, it was found that those licensed dentists were those who failed the most (11\%), and question 14, about the principles on which the dentist-patient relationship is based, where $48.3 \%$ of those with the most education were correct compared to $30 \%$ of those with the least education. It can thus be concluded that no higher level of knowledge was observed in either compulsory or additional academic education, and it can be concluded that there seems to be no relationship between level of education and level of knowledge, these figures are represented in the following Table 1, compulsory and additional academical education knowledge to questions 16 and 14 . 
Table 1

Compulsory and additional academical education knowledge to questions 16 and 14. DNK/NA: Doesn't know/ no answer.

\begin{tabular}{|c|c|c|c|c|c|c|c|c|c|c|c|}
\hline & & \multicolumn{10}{|c|}{ COMPULSORY ACADEMICAL EDUCATION } \\
\hline & & \multicolumn{2}{|c|}{ Total } & \multicolumn{3}{|c|}{ GM } & \multicolumn{2}{|l|}{ LD } & \multicolumn{3}{|c|}{ DG } \\
\hline & & $\mathbf{N}$ & $\%$ & & $\mathbf{N}$ & $\%$ & $\mathbf{N}$ & $\%$ & & $\mathbf{N}$ & $\%$ \\
\hline \multirow{7}{*}{$\begin{array}{l}\text { Q16. When } \\
\text { faced with } \\
\text { the } \\
\text { evidence } \\
\text { of } \\
\text { unqualified } \\
\text { practice: }\end{array}$} & Total & 204 & $100.0 \%$ & & 21 & $100.0 \%$ & 145 & $100.0 \%$ & & 38 & $100.0 \%$ \\
\hline & Incorrect & 16 & $7.8 \%$ & & 0 & $.0 \%$ & 16 & $11.0 \%$ & & 0 & $.0 \%$ \\
\hline & Correct & 187 & $91.7 \%$ & & 21 & $100.0 \%$ & 128 & $88.3 \%$ & & 38 & $100.0 \%$ \\
\hline & DNK/NA & 1 & $.5 \%$ & & 0 & $.0 \%$ & 1 & $.7 \%$ & & 0 & $.0 \%$ \\
\hline & & \multicolumn{10}{|c|}{ ADDITIONAL ACADEMICAL EDUCATION } \\
\hline & & \multicolumn{5}{|c|}{ Total } & \multicolumn{2}{|l|}{ No } & \multicolumn{3}{|l|}{ Yes } \\
\hline & & & & $\mathbf{N}$ & & $\%$ & $\mathbf{N}$ & $\%$ & $\mathbf{N}$ & & $\%$ \\
\hline \multirow{4}{*}{\multicolumn{2}{|c|}{$\begin{array}{l}\text { Q14. The principles in } \\
\text { which the dentist-patient } \\
\text { relationship is based: }\end{array}$}} & \multicolumn{2}{|c|}{ Total } & 204 & & $100.0 \%$ & 30 & $100.0 \%$ & 174 & & $100.0 \%$ \\
\hline & & \multicolumn{2}{|c|}{ Incorrect } & 102 & & $50.0 \%$ & 21 & $70.0 \%$ & 81 & & $46.6 \%$ \\
\hline & & \multicolumn{2}{|c|}{ Correct } & 93 & & $45.6 \%$ & 9 & $30.0 \%$ & 84 & & $48.3 \%$ \\
\hline & & \multicolumn{2}{|c|}{ DNK/NA } & 9 & & $4.4 \%$ & 0 & $.0 \%$ & 9 & & $5.2 \%$ \\
\hline
\end{tabular}

\section{Analysis by specialization}

With regard to the specialisation, the group of respondents who had mentioned General Dentistry as their specialisation showed significant differences in the average score in the ethical knowledge group, where they obtained $65.9 \%$, the second highest average score of all the specialisations, behind that obtained by the specialists in Aesthetics who obtained 69.5\%, but both were much higher than the total average score of all specialisations for this section, which was $61.9 \%$, and by extension, of all the questions answered in the questionnaire, obtaining a total average of $64.9 \%$ for the 3 sections, the second highest of all the specialisations, information represented in the following Table 2, knowledge by specialisation. 
Table 2

Knowledge by specialisation.

\begin{tabular}{|lllll|}
\hline & & \multicolumn{2}{l}{ Specialisation } \\
\hline Ethical knowledge & & Total & General Dentistry & Aesthetics \\
\hline Correct questions in TOTAL/ For the 3 sections & N & 204 & 123 & 58 \\
& Average score & 61.9 & 65.9 & 69.5 \\
\hline
\end{tabular}

Survey respondents working as general dentists showed greater knowledge on some questions, such as question 13 , which dealt with experimentation in the field of pharmacological therapeutics, where this group obtained $81.3 \%$ correct answers, compared to $73 \%$ of the overall sample, and also question 29 , on informed consent, about which this group seemed more knowledgeable, obtaining $92.7 \%$ correct answers, again higher than the total for the rest of the specialisations, which was $89.25 \%$. The results obtained in these individual questions and others, although not reaching the level of significance, accumulated and raised the mean level of knowledge for the total questionnaire for the specialisation of General Dentistry.

Another interesting set of results related to the group of respondents specialising in Aesthetics compared to the rest of the respondents. Up to 3 questions were reported where there were significant differences $(13,16$ and 29$)$ that respectively dealt with experimentation, the crime of unqualified practice and informed consent. It was observed that the group of professionals practising this specialisation got these questions right more than those who did not work in this field (the rates exceeded 93\%), the total percentage of correct answers to question 13 was $73 \%$ and this specialisation obtained $93.1 \%$, being also the specialisation that obtained the best results. As with question 16, in which the percentage of correct answers was $91.7 \%$ and this specialisation obtained $98.3 \%$, or question 29 , in which the total percentage of correct answers was $89.2 \%$, and this specialisation obtained $98.3 \%$, and as with question 13 , this was the specialisation that obtained the best result. These figures can be seen in Table 3, overall and aesthetics knowledge to questions 13, 16 and 29, which is presented below. 
Table 3

Overall and aesthetics knowledge to questions 13, 16 and 29. DNK/NA: Doesn't know/ no answer

\begin{tabular}{|c|c|c|c|c|c|}
\hline & & \multicolumn{2}{|c|}{ Total } & \multicolumn{2}{|c|}{ Aesthetics } \\
\hline & & $\mathbf{N}$ & $\%$ & $\mathbf{N}$ & $\%$ \\
\hline \multirow{4}{*}{$\begin{array}{l}\text { Q13. In the pharmacological therapeutics field, } \\
\text { experimentation is legal when: }\end{array}$} & Total & 204 & $100.0 \%$ & 58 & $100.0 \%$ \\
\hline & Incorrect & 49 & $24.0 \%$ & 4 & $6.9 \%$ \\
\hline & Correct & 149 & $73.0 \%$ & 54 & $93.1 \%$ \\
\hline & DNK/NA & 6 & $2.9 \%$ & 0 & $.0 \%$ \\
\hline \multirow{4}{*}{$\begin{array}{l}\text { Q16. When facing the evidence of an intrusion crime, we } \\
\text { must: }\end{array}$} & Total & 204 & $100.0 \%$ & 58 & $100.0 \%$ \\
\hline & Incorrect & 16 & $7.8 \%$ & 1 & $1.7 \%$ \\
\hline & Correct & 187 & $91.7 \%$ & 57 & $98.3 \%$ \\
\hline & DNK/NA & 1 & $.5 \%$ & 0 & $.0 \%$ \\
\hline \multirow[t]{4}{*}{ Q29. In the consent, the information must include: } & Total & 204 & $100.0 \%$ & 58 & $100.0 \%$ \\
\hline & Incorrect & 20 & $9.8 \%$ & 1 & $1.7 \%$ \\
\hline & Correct & 182 & $89.2 \%$ & 57 & $98.3 \%$ \\
\hline & DNK/NA & 2 & $1.0 \%$ & 0 & $.0 \%$ \\
\hline
\end{tabular}

In the light of these results, certain differences can be seen depending on the specialisation in which the professional works, with those working in General Dentistry and Aesthetics Dentistry indicating that they are more knowledgeable about the aspects of the ethical knowledge section.

\section{Analysis by work experience}

With regard to work experience and level of knowledge, it could be seen that there were no major differences in terms of how long they had worked. The only question with a notable result was question 26 , which referred to the importance of informed consent. Interestingly, with regard to knowledge based on work experience, $63.8 \%$ of those who had been working for 5-10 years were much more likely to get this question right, compared to the beginners, who got $31.4 \%$, and to the more veteran ones, who got $37.7 \%$, represented in the next Table 4, knowledge to question 26 based on work experience. 
Table 4

Knowledge to question 26 based on work experience. DNK/NA: Doesn't know/ no answer.

\begin{tabular}{|c|c|c|c|c|c|c|c|c|c|}
\hline & & \multicolumn{8}{|c|}{ Work experience } \\
\hline & & \multicolumn{2}{|c|}{ Total } & \multicolumn{2}{|c|}{$<5$ years } & \multicolumn{2}{|c|}{$5-10$ years } & \multicolumn{2}{|c|}{$>10$ years } \\
\hline & & $\mathbf{N}$ & $\%$ & $\mathbf{N}$ & $\%$ & $\mathbf{N}$ & $\%$ & $\mathbf{N}$ & $\%$ \\
\hline & DNK/NA & 3 & $1.5 \%$ & 0 & $.0 \%$ & 1 & $2.1 \%$ & 2 & $1.6 \%$ \\
\hline \multirow{4}{*}{$\begin{array}{l}\text { Q26. Which of the } \\
\text { following statements is not } \\
\text { correct about the informed } \\
\text { consent: }\end{array}$} & Total & 204 & $100.0 \%$ & 35 & $100.0 \%$ & 47 & $100.0 \%$ & 122 & $100.0 \%$ \\
\hline & Incorrect & 112 & $54.9 \%$ & 22 & $62.9 \%$ & 16 & $34.0 \%$ & 74 & $60.7 \%$ \\
\hline & Correct & 87 & $42.6 \%$ & 11 & $31.4 \%$ & 30 & $63.8 \%$ & 46 & $37.7 \%$ \\
\hline & DNK/NA & 5 & $2.5 \%$ & 2 & $5.7 \%$ & 1 & $2.1 \%$ & 2 & $1.6 \%$ \\
\hline
\end{tabular}

\section{Analysis by place of work}

With regard to the workplace and level of knowledge, it could be seen that the university teacher was the most heterogeneous background in terms of knowledge with respect to the overall sample, as significant differences were observed in up to three questions. Firstly, they had a lower level of knowledge for question 18, concerning professional secrecy, obtaining an incorrect answer rate of $26.4 \%$, when the percentage of incorrect answers in the whole column was $17.2 \%$, thus obtaining the highest percentage of incorrect answers by far in comparison with the values obtained by all the other workplaces, which had values of $13.3 \%$ or $18.9 \%$, among others.

However, a higher level of knowledge was obtained for questions 23 and 24, relating to the medical history of patients, with $84.9 \%$ correct answers for question 23 , whereas the percentage of correct answers for the total column was $71.9 \%$, thus obtaining the highest percentage of correct answers by far in comparison with the values obtained by all other workplaces. Something similar to what happened with question 24 , which obtained $88.7 \%$ correct answers, when the percentage of correct answers in the total column was $74.9 \%$, obtaining a value much higher than this, as it be seen in the following Table 5, level of knowledge and workplace. 
Level of knowledge and workplace. DNK/NA: Doesn't know/ no answer

\begin{tabular}{|c|c|c|c|c|c|}
\hline & & \multicolumn{4}{|c|}{ WORKPLACE } \\
\hline & & \multicolumn{2}{|c|}{ Total } & \multicolumn{2}{|c|}{$\begin{array}{l}\text { University } \\
\text { teacher }\end{array}$} \\
\hline & & $\mathbf{N}$ & $\%$ & $\mathbf{N}$ & $\%$ \\
\hline \multirow[t]{3}{*}{ Q18. What type of secret does professional secret entail } & Total & 203 & $100.0 \%$ & 53 & $100.0 \%$ \\
\hline & Incorrect & 35 & $17.2 \%$ & 14 & $26.4 \%$ \\
\hline & Correct & 168 & $82.8 \%$ & 39 & $73.6 \%$ \\
\hline \multirow[t]{4}{*}{ Q23. Related to the medical history of a patient } & Total & 203 & $100.0 \%$ & 106 & $100.0 \%$ \\
\hline & Incorrect & 53 & $26.1 \%$ & 29 & $13.2 \%$ \\
\hline & Correct & 146 & $71.9 \%$ & 75 & $84.9 \%$ \\
\hline & DNK/NA & 4 & $2.0 \%$ & 2 & $1.9 \%$ \\
\hline \multirow{4}{*}{$\begin{array}{l}\text { Q24. In the case of a deceased patient, they will have the } \\
\text { right to access their medical history: }\end{array}$} & Total & 203 & $100.0 \%$ & 106 & $100.0 \%$ \\
\hline & Incorrect & 44 & $21.7 \%$ & 29 & $9.4 \%$ \\
\hline & Correct & 152 & $74.9 \%$ & 72 & $88.7 \%$ \\
\hline & DNK/NA & 7 & $3.4 \%$ & 5 & $1.9 \%$ \\
\hline
\end{tabular}

\section{Analysis by position at work (professional category)}

And finally, with regard to the results of the relationship between the professional category and the degree of knowledge, it could be observed that the score in the section on legislation for the self-employed and employees as a whole was different from the rest. In order to better visualise it, Fig. 4 (Graph of knowledge distribution of the self-employed and employees), a graph of knowledge distribution of the self-employed and employees, was drawn up.

This graph shows that knowledge of this professional category was somewhat lower in the section on legislation (grey boxes). One of the questions contributing most to this result was question 22 , which dealt with professional secrecy, which only $58.8 \%$ of this professional category of self-employed and employees got right, compared to $73 \%$ overall, being also the professional category that obtained the lowest percentage of correct answers to this question. Question 30, which dealt with the expert's requirements, was also interesting, with knowledge dropping to $44.1 \%$, compared to $62.7 \%$ overall, again with the lowest percentage of correct answers. It concludes that only one background, that of the self-employed and employees as a whole, demonstrates a lower level of knowledge than the rest of the sample.

\section{Discussion}

With advances in medical sciences and the evolution of the legal system in modern society and patients' awareness of their rights, doctors and other health care workers are frequently caught in difficult predicaments 
arising from their daily practice, such as the duty to respect informed consent, telling the truth, breaches of confidentiality, biomedical research, etc. In addition, there has been growing public concern about the ethical conduct of health professionals, reflected in complaints about their poor ethical conduct and an increase in the resort to lawsuits against them (6). For all these reasons, they should be more familiar with current health legislation and regulations.

In addition, as Hariharan concludes in his article, "there is a need to identify those who appear uninterested in ethical or legal issues" (15). This study was therefore able to identify the background and objectively quantify the level of knowledge of the dentists and stomatologists registered in the Valencian Community on current health legislation and regulations, who obtained overall, a score of 6.34 out of 10 .

Furthermore, the dentists surveyed in the Valencian Community obtained the lowest average number of correct answers, $61.9 \%$, to the questions in the first section, which covered their level of ethical knowledge, demonstrating, as also stated in the study in Adhikari's article, "that a significant proportion of doctors were not aware of the universally recognised ethical principles, which are an essential part of their clinical practice" (16). It should also be remembered that it is sometimes difficult to dissociate the legal and ethical basis of dentists' professional duties, as a moderate general level of knowledge on the part of dentists and stomatologists about current health legislation and regulations may be insufficient to carry out their daily clinical practice safely for both themselves and their patients.

With regard to the level of education and level of knowledge, based on the 2017 article by Blau, I. and Levin L., in which they pointed out that dental care providers are obliged to deal with legal issues and therefore it is essential for doctors and dentists to recognise the basic legal concepts of medical malpractice (12), it was deduced that all dentists should have a minimum knowledge base of legal dentistry to carry out their work. On the other hand, a highly interesting article from 2006, "Knowledge, attitudes and practice of medical students at the Cave Hill Campus in relation to ethics and law in healthcare", concluded in its findings that in general, medical students recognised the importance of ethical knowledge, but felt that they knew little about law, and that they drew knowledge from multiple sources, especially from lectures and seminars, to improve their ethical knowledge (17).

Thus, at the beginning of this study, it was believed that dentists who had received more additional training, through completing various courses, would be more likely to have received more information in some of them about existing health legislation or regulations, and would be able to obtain better results in this test, as opposed to others who had received less additional training. But as shown by the results of this study, level of education did not strongly correlate with level of knowledge.

With regard to specialisation and level of knowledge, the article published by Bordonaba-Leiva $\mathrm{S}$ et al. regarding malpractice claims filed in the last 24 years in the field of Oral and Maxillofacial Surgery in Spain, highlight the growing trend of malpractice claims for adverse events, suggesting that professionals working in Oral and Maxillofacial Surgery are aware of the ongoing problem (11). This initially led us to believe that the dentists and stomatologists specialising in Oral Surgery and Implantology who responded to this survey would obtain better results, as they would likely have to be better informed. Furthermore, these statements are added to what the 2019 article by He P. et al. pointed out, stating that: "surgical specialisations in particular have been shown to carry the highest legal risk, encompassing some of the highest premiums for malpractice" (18), which again made us suspect that those specialising in Oral Surgery and Implantology would perform better, as dental 
extractions are often the main reason for malpractice claims against this group and hence they should be more aware of current legal knowledge, as it can more easily impact on them. However, although there were some differences according to the specialisation of each practitioner, respondents working in General Dentistry and Aesthetics were found to be the most knowledgeable about ethical issues.

With regard to years of work experience and level of knowledge, as observed from the findings of the 2014 article by Dhanappa et al., which stated the importance of and the need for adequate training among graduates to raise their awareness of aspects of legal education and maintaining professional ethical conduct in the field of health (6), it was thought that the newer dentists and stomatologists, having graduated recently, would remember better and thus obtain better results in the survey, having taken the subject responsible for training them in this field, "Legal and Forensic Dentistry", more recently in the Degree of Dentistry. However, after analysing the results of our study, we can conclude that there is no significant correlation between the amount of time spent on the job and the degree of knowledge of the subject.

When considering the relationship between workplace and degree of knowledge, those working as university teachers, who accounted for $26.1 \%$ of the total number of dentists surveyed in the Valencian Community, tended to stand out from the rest of the occupations. It may be because university teachers have the task of sharing their knowledge and teaching not only to future dentists, but also to students of other degrees, postgraduate courses, undergraduate courses, vocational training at different levels related to dentistry, and thus they should be more up to date in this matter. As Bhadauria, US, explains in his 2018 article, understanding the legal aspects not only provides protection against lawsuits, but also provides the practical implication of understanding the significance of dental history, radiographs, photos and dental models, because legally, the dentist's written records carry more weight than the patient's memories (13), and academics also have a moral obligation to know these facts in order to pass them on to their students.

Finally, with regard to the professional category and degree of knowledge, it was initially thought, after reading the article by Perea Pérez B., entitled "Professional liability in oral surgery", that it was evident that the legal pressure from patients was increasing, so we dentists must assume it and try to adopt measures that minimise this risk, or limit its consequences in the event that it should occur. Among the recommendations for minimising the risks of a dental professional liability claim or to limit its consequences were to have a minimum of medicallegal knowledge in order to practise, to know the casuistry of the procedures with the most claims and to take the utmost legal precautions with regard to patients who may be potential claimants (10), that dentists in positions of greater responsibility, being more likely to receive an initial claim or lawsuit, should perform better, being more up to date with health legislation and regulations, than, for example, another dentist or stomatologist who is only dedicated to teaching and who does not work with patients or does so infrequently. However, after conducting our study we were able to confirm that, although there were differences in specific questions regarding the role of the professional, only one background, the self-employed and the employed combined, demonstrated a lower level of knowledge than the overall sample.

Based on the conclusions obtained from this study, new lines of research have arisen in relation to current dental law and expertise. The next step should be to carry out the same survey in other Spanish provinces and thus verify whether the same results are obtained in the different regions, in order to be able to extrapolate the results on a larger scale. 


\section{Conclusions}

1. The level of knowledge of the members in the field of health legislation and regulations is moderate. An average of $63 \%$ of questions answered correctly was barely reached. By thematic areas, the degree of knowledge is similar and moderate in the areas of ethics, legislation and documentation.

2. The level of education is not significantly related to the degree of knowledge.

3. There are certain differences according to the specialisation in which the professional works. Those working in General Dentistry and Aesthetics Dentistry are more knowledgeable about aspects of the section on ethics.

4. No significant correlation was found between the amount of time spent on the job and the degree of knowledge of the subject.

5. With regard to the workplace, it is worth noting that those who work as university teachers tend to stand out from the rest of the professionals in terms of specific issues such as professional secrecy or clinical records, although not in the overall scores or by section. Thus, those who work as university teachers tend to stand out from the rest of the professional activities.

6. With regard to professional role, there are differences in specific questions, but only one background, that of the self-employed and employees as a whole, shows a lower level of knowledge than the rest of the sample.

The conclusions obtained from this study highlight the need for dentists to complete and update their education in ethics and their knowledge of current health regulations, as knowledge of current legislation improves their legal protection.

\section{Abbreviations}

QR code: Quick Response.

IP code or direction: Internet protocol.

LD: Licensed dentist.

DG: Dental graduates.

GM: Graduates in medicine.

DNK/NA: Doesn't know/ no answer.

\section{Declarations}

\section{Ethics approval and consent to participate:}

The Ethics Committee for Biomedical Research of the CEU-Cardenal Herrera University gave approval on 17 December 2019 to carry out this study, with reference number CEI19/154.

As the survey was confidential and was carried out electronically by the participants, this made it impossible to obtain a physical signature on paper regarding informed consent. In the introductory paragraph to the survey, 
which all participants had to read and which contained the instructions for completing the survey, it was stated that it was "ANONYMOUS" and "NO personal data of any kind will be recorded". In this way, by providing study participants with the necessary basic information about the study, all participants provided informed consent and all participants were guaranteed that the principal investigator would be unable to identify the participant at any time, thus ensuring that their data would be treated confidentially, in accordance with the considerations of the Ethics Committee for Biomedical Research of the International Doctoral School CEINDO.

\section{Consent to publication.}

Not applicable

\section{Availability of data and materials:}

Data records used and/or analysed during the current study are available from the relevant author upon reasonable request. Martina Sánchez Gisbert is the corresponding author and who should be contacted email: martina.sanchez@uchceu.es.

\section{Competing interests:}

The authors declare that they have no competing interests.

\section{Funding:}

No funding was received for this study.

\section{Authors' contribution:}

MSG, CCS and MGG participated in the design, conduct and analysis of this study, and contributed to the writing of this manuscript. All authors read and approved the final manuscript.

\section{Acknowledgement:}

We would like to acknowledge the participation of all the dentists and stomatologists who contributed to this study, for the time spent answering the survey and the information provided in the survey.

\section{Authors details (optional):}

Not applicable.

\section{References}


1. Moraes DA, Maluf F, Tauil PL, Portillo JAC. Precarisation of dentistry in private healthcare: bioethical analysis. Cien Saude Colet 2019 Mar;24(3):705-714.

2. Almerich-Silla, JM, Montiel-Company, JM, Rivera-Vega, MI. Technical report of the dental porfession in the province of Valencia. May 2014.

3. FDI World DF. FDI policy statement on the role of the FDI in dental ethics: Adopted by the General Assembly: 24 September 2015, Bangkok, Thailand. Int Dent J 2016 02;66(1):21-22.

4. Wassif HS. Perception of studying dental law and ethics among postgraduate dental students in the $\mathrm{UK}$. $\mathrm{Br}$ Dent J 2015 Aug 14;219(3):131-134.

5. Garbin CA, Garbin AJ, Saliba NA, de Lima DC, de Macedo AP. Analysis of the ethical aspects of professional confidentiality in dental practice. J Appl Oral Sci 2008 Jan-Feb;16(1):75-80.

6. Dhanappa KB, Mn P, Ravi R, Mg J, Deshpande P, Biradar SM. Knowledge, attitudes and practice of healthcare ethics and law among dental graduates at the RV dental college, Bengaluru. J Contemp Dent Pract 2014 Mar 1;15(2):223-228.

7. Avon SL. Forensic odontology: the roles and responsibilities of the dentist. J Can Dent Assoc 2004 JulAug;70(7):453-458.

8. Ryan FS, Cedro MK, Pabari S, Davenport-Jones L, Noar JH. Clinicians' knowledge and practice of data protection legislation and information management. Br Dent J 2009 Jan 24;206(2):1.

9. Radhika T, Nadeem J, Arthi R, Nithya S. Awareness about medico legal aspects and Consumer Protection Act among dentists. J Forensic Odontostomatol 2017 Jul 1;1(35):1-8.

10. Perea Pérez B, Labajo González ME, Santiago Sáez A, Albarrán Juan ME. Professional responsibility in dentistry. Spanish Journal of Legal Medicine 2013 October-December 2013;39(4):149-156.

11. Bordonaba-Leiva S, Gomez-Duran EL, Balibrea JM, Benet-Trave J, Martin-Fumado C, Bescos Atin C, et al. Twenty four years of oral and maxillofacial surgery malpractice claims in Spain: patient safety lessons to learn. Oral Maxillofac Surg 2019 Jun;23(2):187-192.

12. Blau I, Levin L. Medical malpractice: An introduction for the dental practitioner. Quintessence Int 2017;48(10):835-840.

13. Bhadauria US, Dasar PL, Sandesh N, Mishra P, Godha S. Medico-legal aspect of dental practice. Clujul Med 2018 Jul;91(3):255-258.

14. Gisbert Calabuig. Legal Medicine and Toxicology. 7th ed. Spain: Elsevier; 2019.

15. Hariharan S, Jonnalagadda R, Walrond E, Moseley H. Knowledge, attitudes and practice of healthcare ethics and law among doctors and nurses in Barbados. BMC Med Ethics 2006 Jun 9;7:E7-6939-7-7.

16. Samaj Adhikari, Kumar Paudel, Arja R. Aro, Tara Ballav Adhikari, Bipin Adhikari and Shiva Raj Mishra. Knowledge, attitude and practice of healthcare ethics among resident doctors and ward nurses from resource poor settings, Nepal. BMC Med Ethics 2016 Nov. 8;17(1):68.

17. Walrond ER, Jonnalagadda R, Hariharan S, Moseley HS. Knowledge, attitudes and practice of medical students at the Cave Hill Campus in relation to ethics and law in healthcare. West Indian Med J 2006 Jan;55(1):42-47.

18. He P, Mah-Ginn K, Karhade DS, Donoff B, Adeeb N, Gupta R, et al. How Often Do Oral Maxillofacial Surgeons Lose Malpractice Cases and Why? J Oral Maxillofac Surg 2019 Jul 10. 
Figures



\section{Figure 1}

Overall percentage of questions answered correctly, the mean and standard deviation for the Valencian Community. 


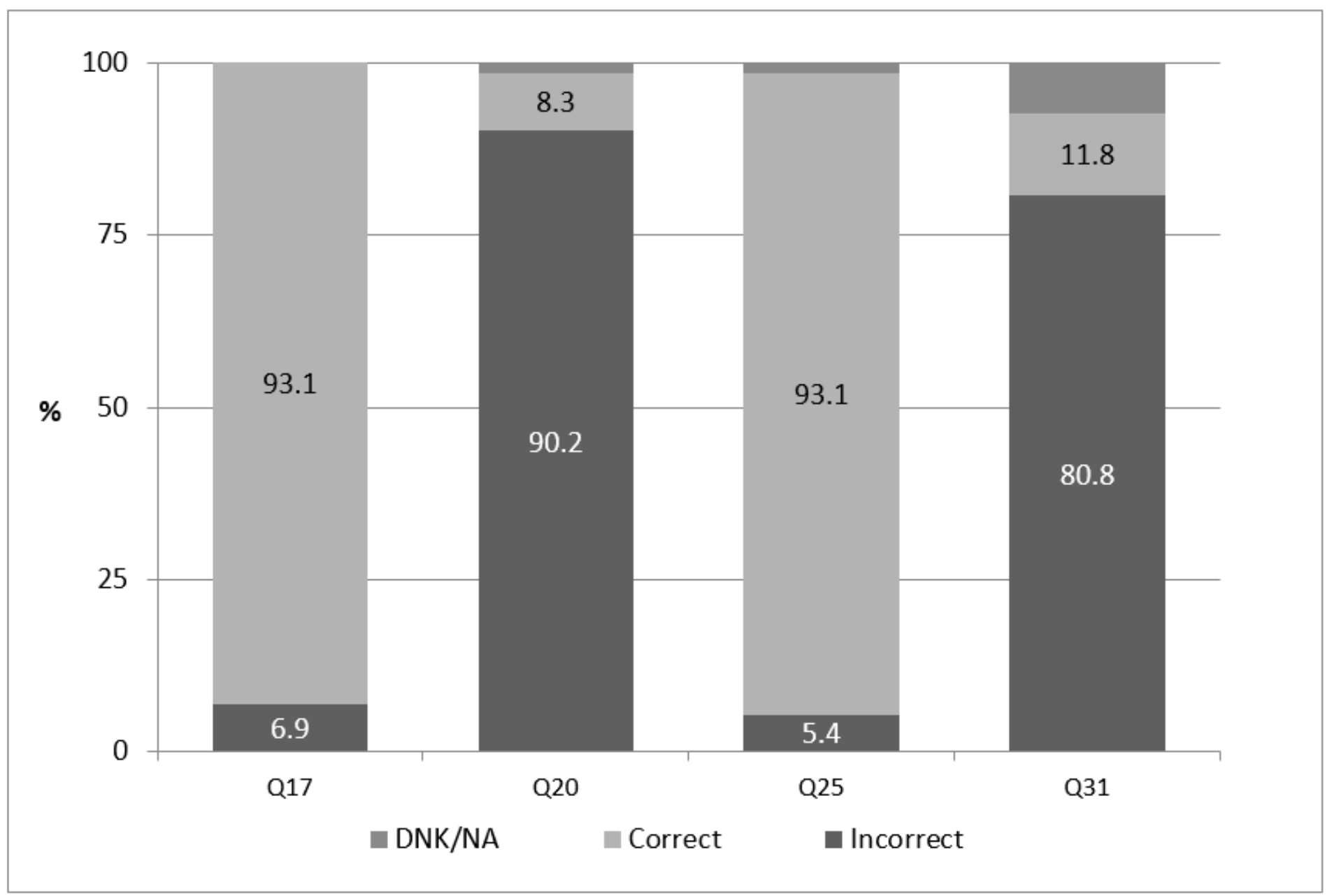

Figure 2

Questions with greatest number of correct, incorrect and DKN/NA responses across all respondents. Q17 and Q25 were most answered correctly. Q20 had the greatest proportion of incorrect answers whilst Q31 had the greatest proportion of DNK/NA answers. DNK/NA: Doesn't know/ no answer. 


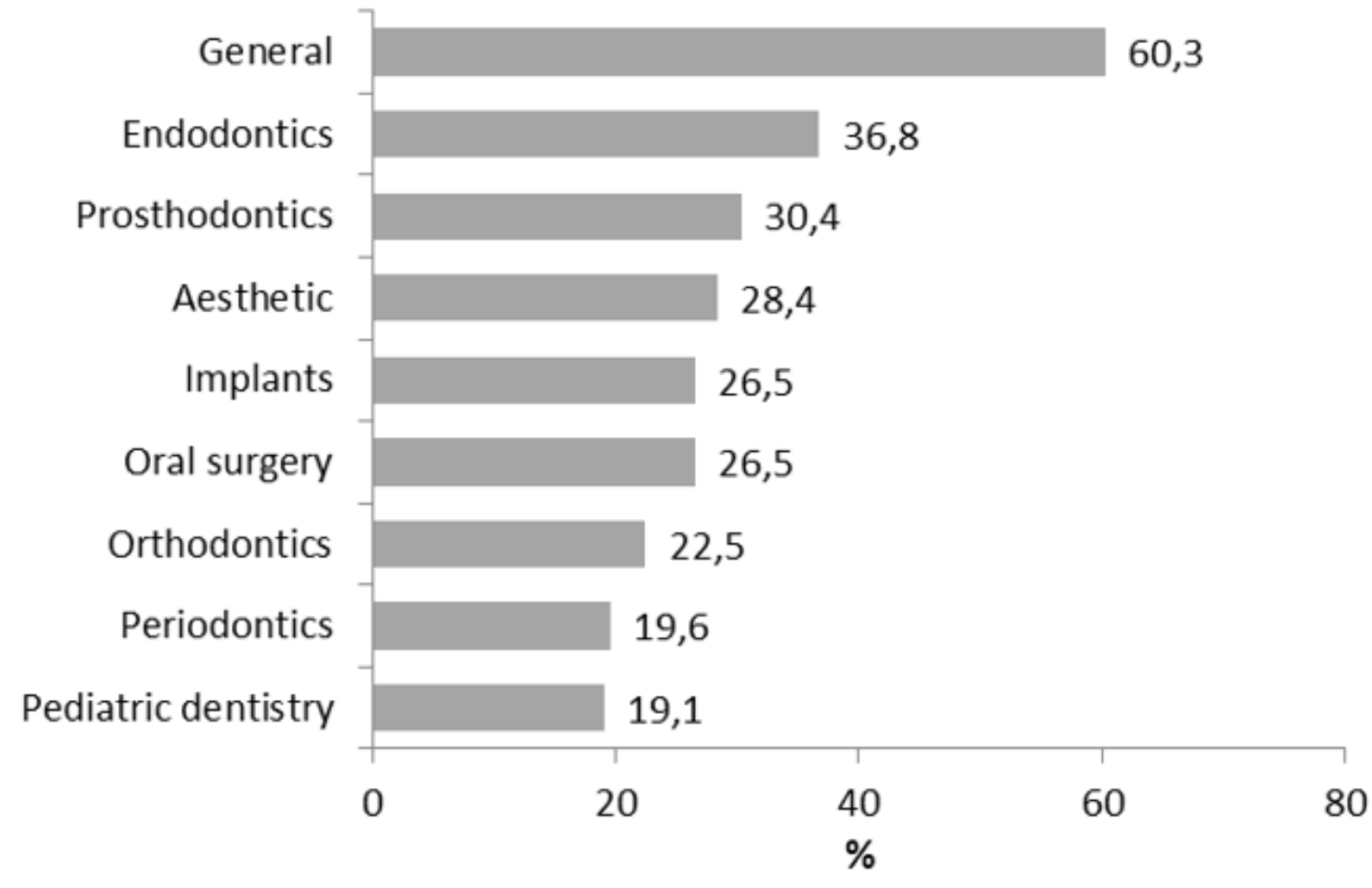

Figure 3

Distribution of the sample by specialisation. 

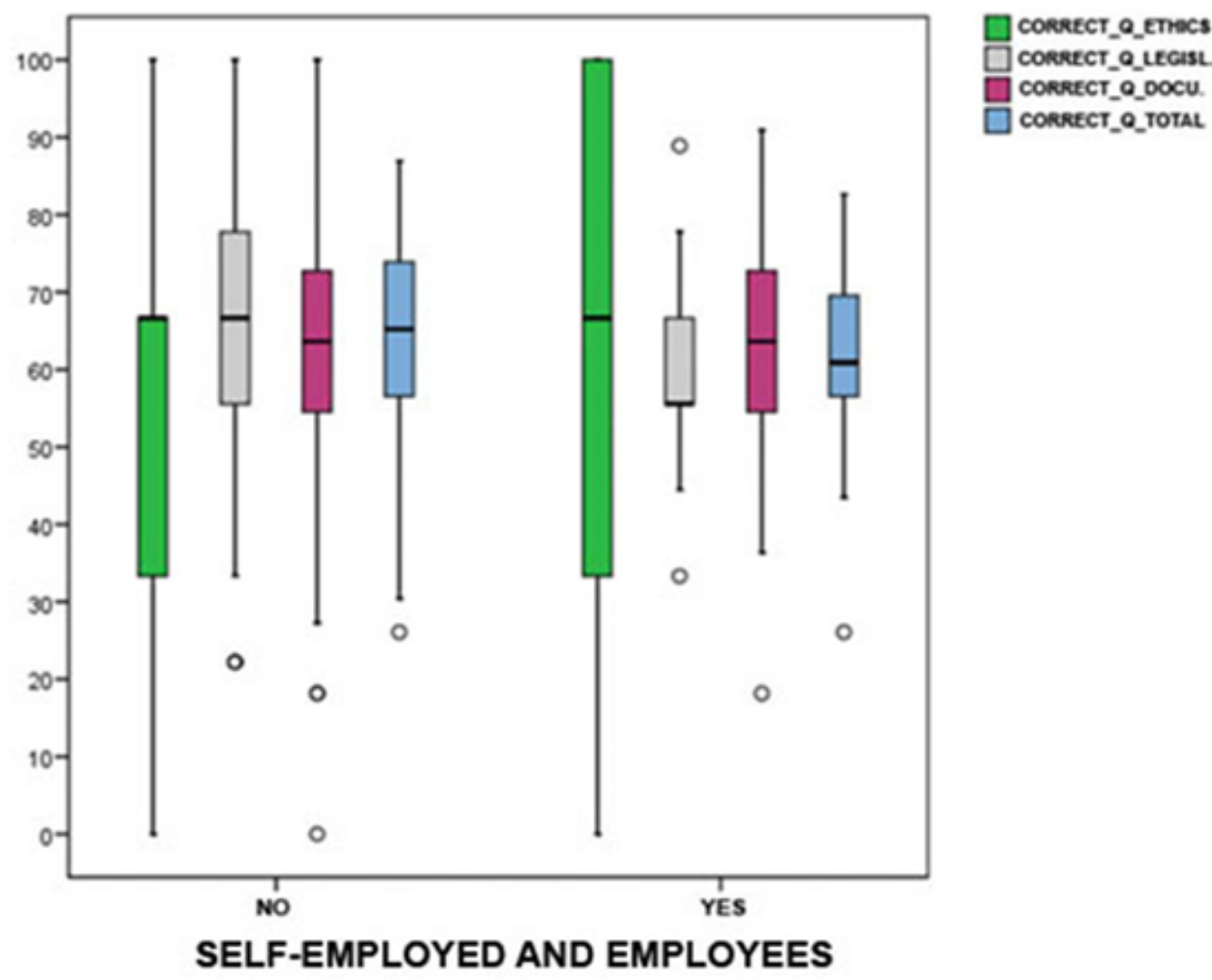

Figure 4

Graph of knowledge distribution of the self-employed and employees.

\section{Supplementary Files}

This is a list of supplementary files associated with this preprint. Click to download.

- Additionalfile1.KAPsurvey.pdf 